\title{
Inorganic arsenic in Chinese food and its cancer risk
}

\author{
Gang Li a , Guo-Xin Sun ${ }^{b}$, Paul N. Williams ${ }^{c}$, Luis Nunes ${ }^{\text {d,* }}$, Yong-Guan Zhu ${ }^{\text {a,b,** }}$ \\ ${ }^{a}$ Key Laboratory of Urban Environment and Health, Institute of Urban Environment, Chinese Academy of Sciences, Xiamen, China \\ b State Key Laboratory of Regional and Urban Ecology, Research Center for Eco-environmental Sciences, Chinese Academy of Sciences, Beijing, China \\ ${ }^{c}$ Lancaster Environment Centre, Lancaster University, Lancaster, UK \\ d Geosystems Center, University of Algarve, 8005-139 Faro, Portugal
}

\section{A R T I C L E I N F O}

\section{Article history:}

Received 13 March 2011

Accepted 9 May 2011

Available online 31 May 2011

\section{Keywords:}

Arsenic

Exposure

Cancer risk

Food

Inorganic

\begin{abstract}
A B S T R A C T
Even moderate arsenic exposure may lead to health problems, and thus quantifying inorganic arsenic (iAs) exposure from food for different population groups in China is essential. By analyzing the data from the China National Nutrition and Health Survey (CNNHS) and collecting reported values of iAs in major food groups, we developed a framework of calculating average iAs daily intake for different regions of China. Based on this framework, cancer risks from iAs in food was deterministically and probabilistically quantified. The article presents estimates for health risk due to the ingestion of food products contaminated with arsenic. Both per individual and for total population estimates were obtained. For the total population, daily iAs intake is around $42 \mu \mathrm{g} \mathrm{day}^{-1}$, and rice is the largest contributor of total iAs intake accounting for about $60 \%$. Incremental lifetime cancer risk from food iAs intake is 106 per 100,000 for adult individuals and the median population cancer risk is 177 per 100,000 varying between regions. Population in the Southern region has a higher cancer risk than that in the Northern region and the total population. Sensitive analysis indicated that cancer slope factor, ingestion rates of rice, aquatic products and iAs concentration in rice were the most relevant variables in the model, as indicated by their higher contribution to variance of the incremental lifetime cancer risk. We conclude that rice may be the largest contributor of iAs through food route for the Chinese people. The population from the South has greater cancer risk than that from the North and the whole population.
\end{abstract}

(c) 2011 Elsevier Ltd. All rights reserved.

\section{Introduction}

Arsenic (As) is one of the first chemicals designated as a group I carcinogen (IARC, 1973), with its severe impacts on human health due to chronic exposure having been widely acknowledged for many years. The epidemiological studies of As disease have arisen in the main from incidences of potable water contamination, which have been linked not only to increases in skin, bladder and lung cancers but also to developmental, cardiovascular and metabolic disorders (Abernathy et al., 1999; Chen et al., 2009; Lubin et al., 2007; NRC, 2001; Smith and Steinmaus, 2009). For example, a study conducted in Inner Mongolia (Northwest China) found that cancer mortality and all-cause mortalities were associated with well-water As exposure, subject to candidates having used the As elevated water sources for over 10 years (Wade et al., 2009). Similarly, in Bangladesh chronic

\footnotetext{
* Correspondence to: L. Nunes, Faculty of Sciences and Technology, Ed. 7, University of Algarve, Gabelas, 8005-139 Faro, Portugal. Tel./fax: + 351289800900.

** Correspondence to: Y.-G. Zhu, Institute of Urban Environment, Chinese Academy of Science, Xiamen, 361021, China, Research Center for Eco-Environmental Sciences, Chinese Academy of Sciences, Beijing 100085, China. Tel./fax: +8610 62936940.

E-mail addresses: luis.nunes.mail@gmail.com (L. Nunes), ygzhu@rcees.ac.cn (Y.-G. Zhu)
}

As exposure via tubewell water is also associated with an increase in all-cause and chronic disease mortality rate (Argos et al., 2010). Whereas a strong dose-response relationship between As in tubewell water and skin lesion development, a precursor of skin cancer, has been observed, with even low exposure to As was shown to be problematic (Ahsan et al., 2006). Low level As intake may also play a role in diabetes prevalence, based on findings from a crosssectional study of 788 adults in the USA (Navas-Acien et al., 2008), in addition to impairing H1N1 infection immune system in responses (Kozul et al., 2009). These research findings amongst others have prompted critical re-evaluation of exposure thresholds for As (WHO/ FAO, 2010).

The principal exposures routes for As are via drinking water, foods and inhaled particulates (Mondal et al., 2010), with many studies detailing the importance of the food pathway to overall As body burdens (Georgopoulos et al., 2007; Meacher et al., 2002; Mondal et al., 2010; Schoof et al., 1999; Xue et al., 2010). In West Bengal (India) it has been shown that even for populations exposed to high As levels in the drinking water, rice constitutes a major source of iAs in the diet (Mondal and Polya, 2008). Yet, rice is the dominant exposure route in all scenarios with seafood also being of importance, especially in those diets without a preference for the grain (Baeyens et al., 2009; CarbonellBarrachina et al., 2009; ESFA, 2009). Indeed understanding iAs exposure 
from rice relies upon the interplay from rice consumption rates, variability in grain As concentrations and the proportion of iAs in the grain (Meharg et al., 2009; Mondal and Polya, 2008).

Rice has been shown to be particularly susceptible to As uptake in comparison with other cereal crops (Williams et al., 2007), reflecting the As levels in the environments in which it is grown. China annually discharges around $195 \mathrm{t}$ of arsenic into the atmosphere from coal power stations alone (Luo et al., 2004). Other prolific, industrial emission sources include mining, non-ferrous metal ores processing and chemical manufacturing (Li et al., 2006a). Far from abating, emission trends will likely be sustained if not increase further in the next few years given China's rapid economic expansion, thereby continuing to threaten food supply chains. We have reported a nationwide survey of As in rice, and found that over $95 \%$ of market rice samples contained less than the national food safety standard of $0.15 \mathrm{iAs} \mathrm{mg} / \mathrm{kg}$ (China Food Standard Agency, 2005); but for rice collected from mining-impacted sites in Hunan and Guangdong provinces a large percentage of the samples failed the national food safety standard (Williams et al., 2009; Zhu et al., 2008a) and this needs to be also considered.

Estimates of dietary iAs exposure for the Chinese population have been attempted, for example Li et al. (2006b) reported that the iAs intake from food by adult males was $1.26 \mu \mathrm{g} / \mathrm{kg}$ body weight, however, rice was not separated from other grains in this analysis. More recently, Meharg et al. (2009) estimated global iAs intakes from rice, calculating the associated excess cancer risk for the Chinese population due to rice consumption to be 152 per 100,000 . This was derived from a sample base of 124 rice samples and modeled using average rice consumption values for China and United States Environmental Protection Agency (USEPA) excess internal cancer risk slopes. However, given the wide ranging variability in dietary habits of sub-populations within China, coupled with the increasing use of rice based ingredients being used in other products such as health-foods, non-dairy alternatives to milk and snack foods (ESFA, 2009; Meharg et al., 2008; Sun et al., 2009), the range of iAs exposures via all food groups and therefore associated cancer risks could be considerable and is currently unclear.

The present study therefore aims to address this issue, by compiling a database of iAs in Chinese food, to quantify at the national and regional level trends in average iAs intake. Furthermore, we propose to model increasing lifetime cancer risks for individuals and the total population due to the ingestion of iAs via food.

\section{Materials and methods}

\subsection{Food consumption data}

Trends in regional and national dietary habits were taken from the 2002 China National Nutrition and Health Survey (CNNHS) (Jin, 2008). This database is China's principal nutrition reference source, containing the dietary patterns of 68,962 individuals from 31 provinces (excluding Hong Kong, Taiwan and Macau). Based on consumption frequency in order to reflect the most commonly consumed products, the food types are categorized into one of 10 groupings: rice, flour, coarse cereal, pulses, vegetables, fruit, meat, milk, eggs, and aquatic products. Categorization of sub-population followed three themes: i) urban vs. rural ii) geographic segregation, i.e. Northern vs. Southern China iii) proximity to the sea, i.e. coastal vs. inland (Further details are provided in the Supplementary data, Table S1). In brief, standard economic development criteria like like gross industrial product, gross domestic product and local financial revenues were used to differentiate, urban and rural areas (Liu et al., 2003). Classification of North and South China was achieved using a geographical divide running from the Huai river to the Qinling mountains (Han et al., 2009), while the coastal and inland regions were categorized by the location of the province. The food consump- tion rates of the whole nation and the urban and rural categories were directly obtained from the CNNHS survey report (Jin, 2008); those of the other two regions (north and south, coastal and inland) were calculated by weighting the population proportion of the involved provinces (Tables S1-S3). For example, the food consumption of the north region was obtained by the following formula: food consumption rate $=\sum \mathrm{R} \times \mathrm{PR}$ : food consumption rate of the province in north region; $\mathrm{P}$ : the proportion of the province in the north region.

\section{2. iAs concentrations in different types of food}

The database of iAs concentrations in different food types was compiled from the published literature. As shown in Table S4 as Supplementary data, a total of 13,684 data points for iAs concentrations were collected. Due to the lack of original data, statistics for iAs concentration for food types other than rice was used for arsenic exposure.

Data for total arsenic concentrations in rice from our dataset (494 samples, Table S4, Supplementary data) was converted to inorganic arsenic concentration by using the regression equations reported in the Supplementary data, Fig. S1 in accordance with the method of Meharg et al. (2009). Because a portion of the data featuring total and inorganic arsenic concentrations in rice was obtained from the literature and based on dry weight, while rice consumption rate is on fresh weight, we converted the concentrations based on dry weight into equivalent fresh weight concentration, with the assumption that water content of rice grain is 10\% (Williams et al., 2005).

The iAs concentrations in vegetables, fruit, meat, milk, eggs and aquatic products were based on wet weight. Milk powder was converted into fresh milk during the calculation. Meanwhile, for the variation of iAs in meat and aquatic products, the mean iAs concentrations in them were calculated by weighting their supply from FAO statistical databases (FAOSTAT, 2005).

\subsection{Calculation of estimated daily intake of iAs (EDI)}

To determine the iAs exposure through food, we calculated the estimated daily intake of iAs by multiplying daily food consumption rate with corresponding iAs residues according to the following equation:

$\mathrm{EDI}_{\mathrm{iAs}}=\sum\left(\mathrm{C}_{\mathrm{i}} \times \mathrm{IR}_{\mathrm{i}}{ }^{i}\right)$

Where EDI is estimated daily intake of iAs ( $\mu \mathrm{g} /$ day); $C_{i}$ is inorganic As concentration in subscripted food $(\mathrm{mg} / \mathrm{kg})$; i refers to different types of food (rice, flour, coarse cereal, pulses, vegetables, fruit, meat, milk, eggs, and aquatic products); $\mathrm{IR}_{\mathrm{i}}$ is the ingestion rate for the subscripted food (g/day), which is the amount of food item consumed per day (Jin, 2008).

We calculated the daily iAs intake with the assumption that the contribution to iAs of some food types like oil, salt, sugar and pastry was neglected, and the main food types were involved, which accounted for about $85 \%$ of the total intake amount (Jin, 2008).

Table 1

Variables used in the deterministic risk model.

\begin{tabular}{ll}
\hline Variables & Parameter characteristics \\
\hline ED (year) & Constant $=70$ \\
EF (day) & Constant $=365$ \\
C $(\mathrm{mg} / \mathrm{kg})$ & From the published literature listed in \\
& Supplementary data, Table S4 \\
IR $(\mathrm{g} / \mathrm{day})$ & From Table 3 obtained from Jin (2008) \\
LT (year) & Constant $=25,550$ \\
BW $(\mathrm{kg})$ & Constant $=60$ \\
CSF $($ per $\mathrm{mg} / \mathrm{kg} / \mathrm{d})$ & Constant $=1.50$ (ATSDR, 2010; USEPA, 2010) \\
\hline
\end{tabular}


Table 2

Variables used in the probabilistic risk model. ${ }^{\mathrm{a}}$

\begin{tabular}{|c|c|c|c|}
\hline Variables & \multicolumn{2}{|c|}{ Assumed probabilistic density function } & Observations \\
\hline BW men $(\mathrm{kg})$ & \multicolumn{3}{|l|}{$\begin{array}{l}\text { Custom from data } \\
\text { (Yang et al., 2005) }\end{array}$} \\
\hline BW women $(\mathrm{kg})$ & \multicolumn{3}{|l|}{$\begin{array}{l}\text { Custom from data } \\
\text { (Yang et al., 2005) }\end{array}$} \\
\hline ED (year) & \multicolumn{3}{|l|}{$\begin{array}{l}\text { Custom from data } \\
\text { (NBS, 2007) }\end{array}$} \\
\hline EF (day) & \multicolumn{3}{|l|}{ Constant $=365$} \\
\hline LT (day) & \multicolumn{3}{|l|}{ Constant $=25,550$} \\
\hline $\mathrm{IR}_{\mathrm{i}}(\mathrm{g} / \mathrm{d})$ & North & South & \\
\hline $\mathrm{IR}_{\text {rice }}$ & $\mathrm{LN}(4.85 ; 5.01)$ & $\begin{array}{l}W(-58.48 \\
409.36 ; 5.27)\end{array}$ & \multirow{10}{*}{$\begin{array}{l}\text { Adjusted } \\
\text { to data; } \\
\text { constrained to } \\
\text { only positive } \\
\text { values }\end{array}$} \\
\hline $\mathrm{IR}_{\text {flour }}$ & $\mathrm{N}(255.8 ; 10170.7)$ & $W(4.10 ; 52.33 ; 0.97)$ & \\
\hline $\mathrm{IR}_{\text {coarse cereal }}$ & $\mathrm{W}(0.0 ; 41.0 ; 0.97)$ & $\mathrm{W}(0.0 ; 5.70 ; 0.48)$ & \\
\hline $\mathrm{IR}_{\text {pulses }}$ & $\mathrm{W}(-0.38 ; 15.29 ; 1.52)$ & $\operatorname{LN}(2.81 ; 0.33)$ & \\
\hline $\mathrm{IR}_{\text {vegetables }}$ & $\mathrm{N}(236.1 ; 4723.8)$ & $\mathrm{N}(318.5 ; 6768.7)$ & \\
\hline $\mathrm{IR}_{\text {fruit }}$ & $\mathrm{W}\left(-0.64 ; 6^{\prime} .0 ; 1.20\right)$ & $\mathrm{W}(0.30 ; 39.75 ; 0.96)$ & \\
\hline $\mathrm{IR}_{\text {meat }}$ & $\mathrm{W}(-0.56 ; 60.14 ; 1.57)$ & $\mathrm{LN}(4.56 ; 0.17)$ & \\
\hline $\mathrm{IR}_{\text {milk }}$ & $\mathrm{W}(0.0 ; 36.24 ; 0.81)$ & $\mathrm{W}(0.0 ; 17.04 ; 0.64)$ & \\
\hline$I_{\text {eggs }}$ & $\mathrm{N}(30.58 ; 241.5)$ & $\operatorname{LN}(3.18 ; 3.22)$ & \\
\hline $\mathrm{IR}_{\text {aquatic products }}$ & $\mathrm{N}(18.28 ; 512.1)$ & $W(0.0 ; 45.75 ; 0.97)$ & \\
\hline \multicolumn{4}{|c|}{$C_{\mathrm{j}}$ (iAs $\mathrm{mg} / \mathrm{kg}$ ) } \\
\hline $\mathrm{C}_{\text {rice }}$ & $\mathrm{N}(0.092 ; 0.020)$ & $\mathrm{LN}(0.099 ; 0.042)$ & \multirow{13}{*}{$\begin{array}{l}\text { Adjusted } \\
\text { to data; } \\
\text { constrained to } \\
\text { values above the } \\
\text { detection limit } \\
(0.0075 \mathrm{mg} / \mathrm{kg})\end{array}$} \\
\hline $\mathrm{C}_{\text {flour }}$ & Constant $=0.075$ & Constant $=0.075$ & \\
\hline $\mathrm{C}_{\text {coarse cereal }}$ & $\mathrm{N}(0.06 ; 0.0596)$ & $\mathrm{N}(0.06 ; 0.0596)$ & \\
\hline$C_{\text {pulses }}$ & $\mathrm{N}(0.0094 ; 0.0049)$ & $\mathrm{N}(0.0094 ; 0.0049)$ & \\
\hline $\mathrm{C}_{\text {vegetables }}$ & $\mathrm{N}(0.0110 ; 0.0190)$ & $\mathrm{N}(0.0110 ; 0.0190)$ & \\
\hline $\mathrm{C}_{\text {fruit }}$ & $\mathrm{N}(0.008 ; 0.0113)$ & $\mathrm{N}(0.008 ; 0.0113)$ & \\
\hline $\mathrm{C}_{\text {meat }}$ & $\mathrm{N}(0.174 ; 0.290)$ & $\mathrm{N}(0.174 ; 0.290)$ & \\
\hline $\mathrm{C}_{\text {milk }}$ & $\mathrm{N}(0.0210 ; 0.1364)$ & $\mathrm{N}(0.0210 ; 0.1364)$ & \\
\hline$C_{\text {eggs }}$ & $\mathrm{N}(0.0180 ; 0.0171)$ & $\mathrm{N}(0.0180 ; 0.0171)$ & \\
\hline$C_{\text {freshwater fish }}$ & $\mathrm{N}(0.0280 ; 0.0310)$ & $\mathrm{N}(0.0280 ; 0.0310)$ & \\
\hline$C_{\text {marine fish }}$ & $\mathrm{N}(0.0090 ; 0.0098)$ & $\mathrm{N}(0.0090 ; 0.0098)$ & \\
\hline $\mathrm{C}_{\text {shellfish }}$ & $\mathrm{N}(0.970 ; 0.1153)$ & $\mathrm{N}(0.970 ; 0.1153)$ & \\
\hline$C_{\text {sea food }}$ & $\mathrm{N}(0.1710 ; 0.0897)$ & $\mathrm{N}(0.1710 ; 0.0897)$ & \\
\hline CSF (per mg/kg/d) & Constant $=1.50$ & & $\begin{array}{l}\text { As indicated by } \\
\text { (ATSDR, 2010; } \\
\text { USEPA, 2010) }\end{array}$ \\
\hline
\end{tabular}

a LN means Lognormal distribution; W represents Weibull distribution; $\mathrm{N}$ means normal distribution; $C_{j}$ stands for iAs concentration in the item of " $\mathrm{j}$ ".

\subsection{Cancer risk calculation}

Incremental Lifetime Cancer Risk (ILTR) is calculated by the following equation,

$\mathrm{ILTR}=\frac{\mathrm{ED} \times \mathrm{EF} \times\left(\sum_{\mathrm{i}} \mathrm{IR}_{\mathrm{i}} \times \mathrm{C}_{\mathrm{i}}\right)}{\mathrm{BW} \times \mathrm{LE}} \times \mathrm{CSF}$

where ILTR is the cancer risk; ED is the exposure duration (year); EF is the exposure frequency (day); BW is the body weight; LE is the life expectancy of the exposed person (day); CSF (cancer slope factor) is the oral cancer slope factor for iAs (per mg/kg/day) (ATSDR, 2010; USEPA, 2010). The details for the parameters characteristics in the equation are shown in the following two paragraphs.

ILTR was determined for an average adult individual (deterministic model) and for the entire population (probabilistic model). For the first estimate, all variables in the equation take a single value, representative of exposure for an adult with $60 \mathrm{~kg}$ during his lifetime (lifetime cancer risk) and therefore represent the risk for these specific conditions (Table 1 ).

Population risk is obtained by assuming some of the variables as probabilistic, i.e., instead of taking single values, these may take any value from a predefined statistical distribution. Hence, population cancer risk is the risk calculated for the entire population, considering all its variability. The parameters used in the probabilistic risk model were indicated in Table 2. A more detailed description of the probabilistic risk model involved is included in the Supplementary data, Section 1 . Both risk measures were necessary as for some regions of the country the required statistical information was not available.

\subsection{Sensitivity analysis}

The sensitivity of each variable in the probabilistic calculation was assessed by calculating the parameters between each input and output during simulations and then evaluating each input contribution to the output variance by squaring the output variance and normalizing to $100 \%$. The Monte Carlo simulation and sensitivity analysis were implemented using Crystal Ball ${ }^{\circ}$ (Oracle, Oracle Corporation, Denver, Colorado, USA. 2010).

\section{Results \\ 3.1. Chinese dietary patterns}

Except for the population from the North, rice is the largest dietary component (Table 3). Vegetable intake was nearly the same for the whole population, although the actual varieties of vegetables may vary between regions. Rural population trends show much lower intake of fruits, meat, milk and aquatic products. Populations from Inland and Northern regions had much lower intake of aquatic products, and the population from the South had much higher intake of rice and lower intake of flour than other regions.

\subsection{Inorganic arsenic in different food groups}

A total of 13,684 data points for inorganic arsenic in Chinese food was compiled based on the published literature (Supplementary data, Table S4). The highest inorganic As (iAs) concentration was found to be $3.599 \mathrm{mg} / \mathrm{kg}$ in shellfish, and in flour the mean was $0.015 \mathrm{mg} / \mathrm{kg}$. Rice generally contained high iAs with a mean value of $0.103 \mathrm{mg} / \mathrm{kg}$, very similar to that of aquatic products $(0.112 \mathrm{mg} / \mathrm{kg})$. iAs concentrations in non-rice plant food were much lower than in rice, and the lowest mean iAs concentration of $0.015 \mathrm{mg} / \mathrm{kg}$ was found in wheat flour.

Table 3

Average estimate daily intake for inorganic arsenic (iAs) through main routes for populations from different regions.

\begin{tabular}{|c|c|c|c|c|c|c|c|c|c|c|c|c|c|c|c|}
\hline \multirow[t]{2}{*}{ Food types } & \multirow{2}{*}{$\begin{array}{l}\text { iAs } \\
\text { concentration } \\
(\mathrm{mg} / \mathrm{kg})\end{array}$} & \multicolumn{7}{|c|}{ Food intake rate $(\mathrm{g} / \mathrm{day})^{\mathrm{a}}$} & \multicolumn{7}{|c|}{ Daily iAs intake $(\mu \mathrm{g} / \mathrm{day})^{\mathrm{b}}$} \\
\hline & & National & Urban & Rural & North & South & Coastal & Inland & National & Urban & Rural & North & South & Coastal & Inland \\
\hline Rice & 0.103 & 238.30 & 217.80 & 246.20 & 123.82 & 326.65 & 235.09 & 244.63 & 24.54 & 22.43 & 25.36 & 12.75 & 33.65 & 24.21 & 25.20 \\
\hline Flour & 0.015 & 140.30 & 131.90 & 143.50 & 249.38 & 55.85 & 117.31 & 151.32 & 2.10 & 1.98 & 2.15 & 3.74 & 0.84 & 1.76 & 2.27 \\
\hline Coarse cereal & 0.06 & 23.60 & 16.30 & 26.40 & 38.97 & 13.17 & 22.29 & 24.95 & 1.42 & 0.98 & 1.58 & 2.34 & 0.79 & 1.34 & 1.50 \\
\hline Pulses & 0.036 & 16.00 & 15.50 & 16.30 & 12.95 & 19.71 & 17.10 & 16.78 & 0.58 & 0.56 & 0.59 & 0.47 & 0.71 & 0.62 & 0.60 \\
\hline Vegetables & 0.0254 & 276.20 & 251.90 & 285.60 & 232.57 & 308.91 & 260.05 & 286.78 & 7.02 & 6.40 & 7.25 & 5.91 & 7.85 & 6.61 & 7.28 \\
\hline Fruit & 0.0136 & 45.00 & 69.40 & 35.60 & 50.85 & 39.06 & 65.68 & 34.41 & 0.61 & 0.94 & 0.48 & 0.69 & 0.53 & 0.89 & 0.47 \\
\hline Meat & 0.024 & 78.60 & 104.40 & 68.70 & 49.12 & 105.45 & 94.24 & 76.89 & 1.89 & 2.51 & 1.65 & 1.18 & 2.53 & 2.26 & 1.85 \\
\hline Milk & 0.021 & 26.60 & 65.80 & 11.40 & 33.38 & 22.24 & 32.65 & 25.62 & 0.56 & 1.38 & 0.24 & 0.70 & 0.47 & 0.69 & 0.54 \\
\hline Eggs & 0.018 & 23.70 & 33.30 & 20.00 & 31.14 & 22.70 & 31.68 & 23.89 & 0.43 & 0.60 & 0.36 & 0.56 & 0.41 & 0.57 & 0.43 \\
\hline Aquatic products & 0.112 & 29.60 & 44.90 & 23.70 & 19.90 & 42.28 & 63.26 & 18.98 & 3.32 & 5.03 & 2.65 & 2.23 & 4.73 & 7.08 & 2.13 \\
\hline Total intake ( $\mathrm{g}$ for food, $\mu \mathrm{g}$ for iAs) & & 897.90 & 951.20 & 877.40 & 842.08 & 956.02 & 939.35 & 904.25 & 42.46 & 42.81 & 42.32 & 30.57 & 52.50 & 46.03 & 42.26 \\
\hline
\end{tabular}

a The data for food intake rate was adapted from Jin (2008). See Supplementary data, Tables S1-S3 for more details.

b iAs intake was calculated by multiplying the food intake rate by the mean iAs concentration from Supplementary data, Table S4. 


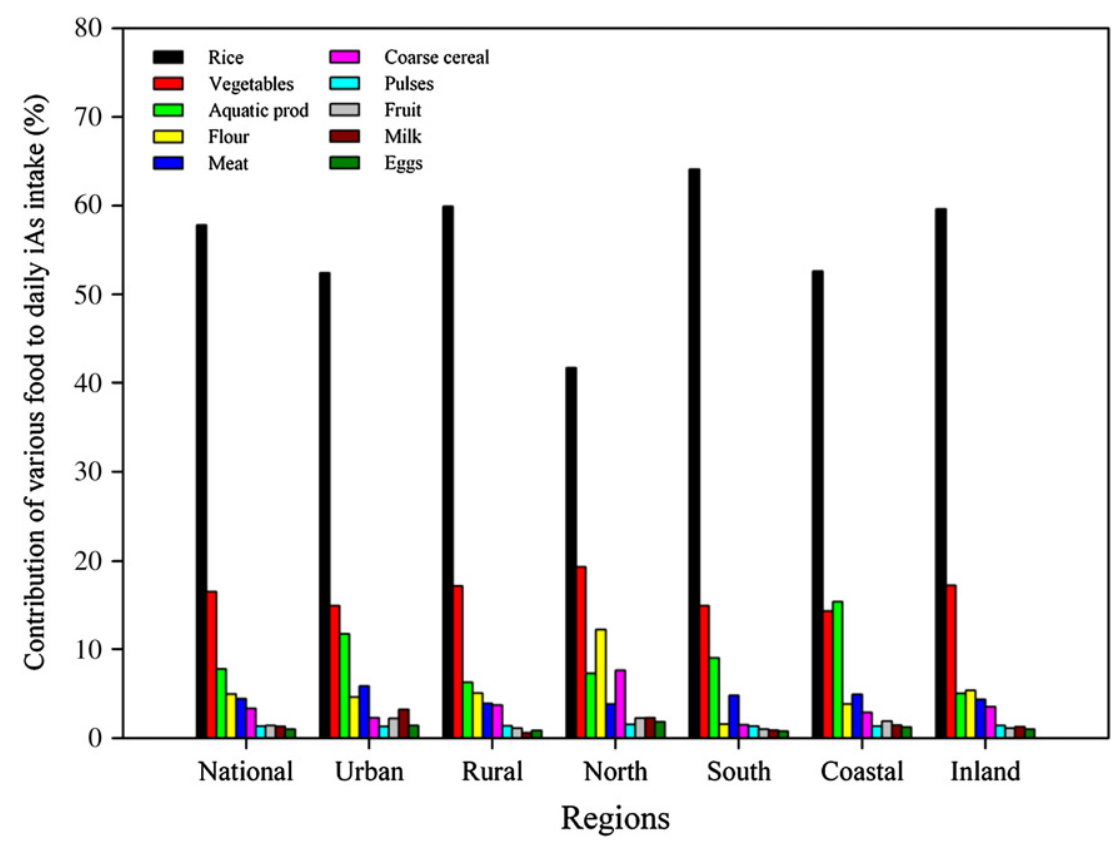

Fig. 1. Contribution of various foods to daily iAs intake in different regions.

\subsection{Estimated daily intake of inorganic arsenic}

Based on the national nutrition and health survey in China, average daily intake for iAs was calculated; the data are listed in Table 3. There was a large variation in iAs intake between regions. The people from the North had the lowest iAs intake of around $30 \mu \mathrm{g} / \mathrm{day}$, whereas from the South they had the highest of over $50 \mu \mathrm{g} / \mathrm{day}$. For the whole population daily iAs intake was $42.46 \mu \mathrm{g} / \mathrm{day}$, and populations in rural and urban had comparable daily iAs intake.

The breakdown of iAs contributions from different food groups also varied between regions. In general, rice is the main contributor of iAs intake. For the total population, rice represented the largest source of iAs accounting for 58\%, followed by vegetables and aquatic products (Fig. 1). For the population in the North, rice contributed $41.7 \%$ of the total iAs intake, with vegetables and flour also being of importance. In contrast, rice contributed $64.1 \%$ of the total iAs intake for the South, followed by vegetables and aquatic products. Except for the coastal region, aquatic products contributed less than $10 \%$ of iAs intake.

\subsection{Estimated cancer risk from iAs in food}

Weekly iAs intake from food ranged from 3.29 to $6.13 \mu \mathrm{g} / \mathrm{kg}$ BW. Weekly iAs intake from food for the total population was $4.95 \mu \mathrm{g} / \mathrm{kg}$ BW, accounting for over $30 \%$ of the provisional tolerable weekly intake (PTWI). The values of estimated ILTR are presented in Table 4.
Probability density functions (pdfs) for lifetime risk for national, Northern, and Southern populations are shown in Fig. 2. The pdfs were distinguishably different between regions, as for the Northern population the ILTR was more concentrated towards the very low values with a long tail to the right; whereas the ILTR for the Southern population had a less markedly skewed distribution. The whole national population showed a pdf with an intermediate behavior, which indicated that an important fraction of the population was exposed to very high risk, as reflected by the long tail toward high values. In fact, $5 \%$ of the population had an incremental cancer risk of between less than 495 per 100,000 and 420 per 100,000 (see Supplementary data, Table S5). Given the non-Normality of ILTR pdf, the median value was used here as the measure of population risk.

Individual adult ILTR from food iAs intake was 106 per 100,000, while population incremental cancer risk was 177 per 100,000 (Table 4). The population from the North had the lowest cancer risk of 123 per 100,000 , while that from the South had the highest cancer risk of 201 per 100,000. Except for the populations in the North and the South, the individual cancer risk from food iAs intake was nearly the same for other regions (Table 4; Fig. 2).

\subsection{Sensitivity analysis}

Sensitivity analysis showed that iAs concentration in rice and aquatic products, ingestion rates for rice and aquatic products (Fig. 3), and cancer slope factor are the

Table 4

Food consumption rate and excess internal cancer risk in different regions of China.

\begin{tabular}{|c|c|c|c|c|c|c|c|}
\hline Region & $\begin{array}{l}\text { Per capita daily food } \\
\text { consumption }(\mathrm{g} / \mathrm{cap} / \mathrm{d})\end{array}$ & $\begin{array}{l}\text { Daily iAs intake per body } \\
\text { weight }(\mu \mathrm{g} / \mathrm{kg} \mathrm{BW})^{\mathrm{a}}\end{array}$ & $\begin{array}{l}\text { Weekly iAs intake per } \\
\text { body weight }(\mu \mathrm{g} / \mathrm{kg} \mathrm{BW})^{\mathrm{a}}\end{array}$ & PTWI $(\mu \mathrm{g} / \mathrm{kg} \text { BW })^{\mathrm{b}}$ & $\mathrm{RfD}(\mu \mathrm{g} / \mathrm{kg} \text { BW/day })^{\mathrm{c}}$ & 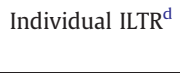 & Population ILTR ${ }^{d}$ \\
\hline National & 897.9 & 0.71 & 4.95 & & & $1.06 \times 10^{-3}$ & $1.77 \times 10^{-3}$ \\
\hline Urban & 951.2 & 0.71 & 4.99 & & & $1.07 \times 10^{-3}$ & - \\
\hline Rural & 877.4 & 0.71 & 4.94 & & & $1.06 \times 10^{-3}$ & - \\
\hline North & 858.3 & 0.47 & 3.29 & 15 & 0.3 & $0.76 \times 10^{-3}$ & $1.23 \times 10^{-3}$ \\
\hline South & 956.0 & 0.88 & 6.13 & & & $1.31 \times 10^{-3}$ & $2.01 \times 10^{-3}$ \\
\hline Coastal & 939.4 & 0.77 & 5.37 & & & $1.15 \times 10^{-3}$ & - \\
\hline Inland & 904.3 & 0.70 & 4.93 & & & $1.06 \times 10^{-3}$ & - \\
\hline
\end{tabular}

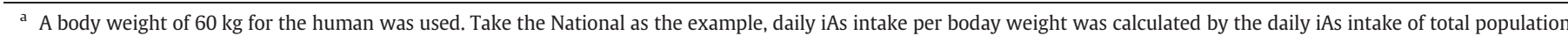

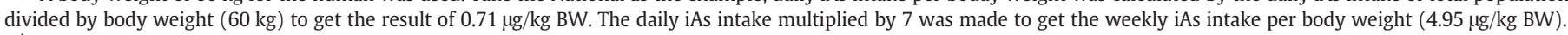

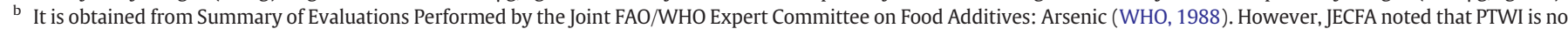
longer appropriate to assess the risk exposure to iAs early last year (WHO/FAO, 2010).

c Reference dose (RfD) of inorganic arsenic is adapted from Integrated Risk Information System (IRIS) of USEPA (IRIS, 1988) http://www.epa.gov/ncea/iris/subst/0278. htm\#reforal.

$\mathrm{d}$ The deterministic and probabilistic ILTR was calculated from the equation presented in Materials and methods, and more details are indicated in Supplementary data, Section 1.

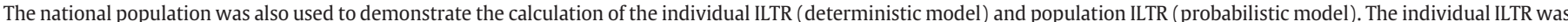

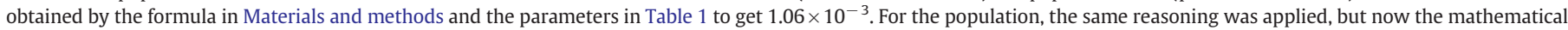

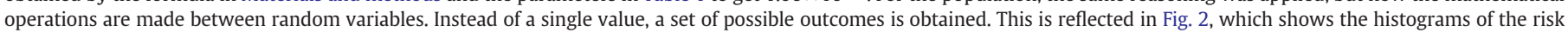
estimates for the two regions and the national. The figure also indicated the 50th and 95th percentiles. The value of population ILTR in the table is the median cancer risk. 


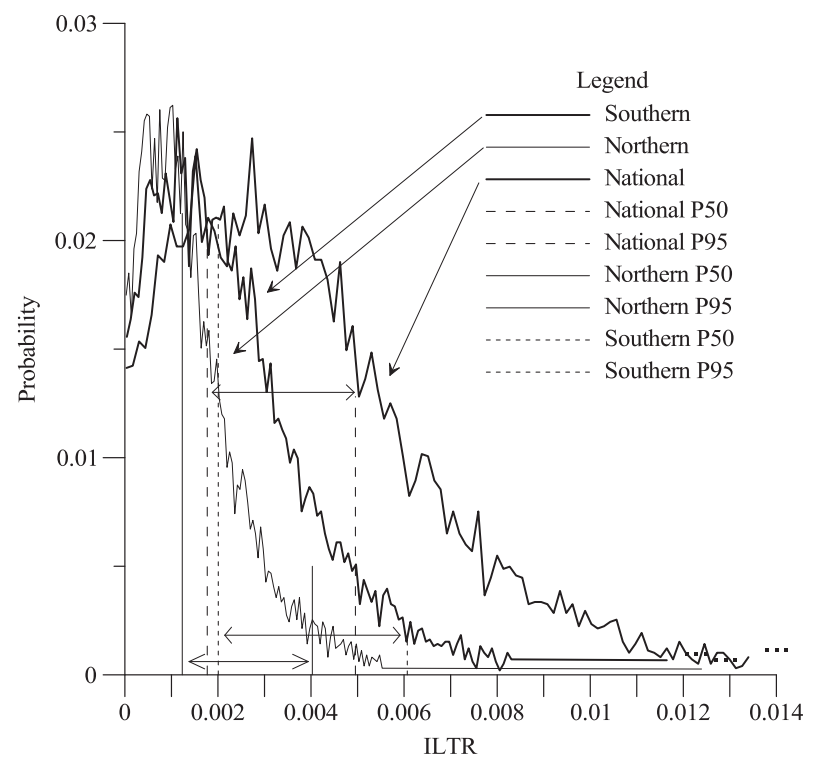

Fig. 2. Probability density functions for ILTR. The 50th and 95th percentiles are also indicated.

most relevant variables. Data for CSF from several sources is presented in Supplementary data, Table S6. Results from uncertainty analysis showed that relatively small change in the values of the concentration of iAs in rice and cancer slope factor may cause important alterations in the estimates (Supplementary data, Section 2 and Fig. S2), being that the impact was greater for higher percentiles (Supplementary data, Table S7 and Fig. S2). These results are in agreement with the observed sensitivity of the model to the values of the same variables. Given the sensitivity of the model to iAs concentration in rice, the better its statistical distribution is characterized, the less prone to errors the risk estimates will be, as small differences in the value of the concentration will be reflected in relatively large differences in the value of the risk estimate.

\section{Discussion}

Cancer risk from food iAs intake in China has not been assessed so far at the national level. Through collating literature data and based on the national nutrition survey, this study provides a framework for assessing the health risk of food iAs in China. In the present study, we constructed a detailed breakdown of food types for populations from different regions in China enabling the fractionation of dietary iAs intake. This study presents estimates for health risk due to the ingestion of food products contaminated with arsenic, both per individual and for total population. The total dietary iAs intake estimated in this study is somewhat lower than that reported by Li et al. (2006b), which might be due to the fact that they combined all cereals together leading to possible overestimation, as rice contain 10-fold more iAs than other cereals (Williams et al., 2007). The weekly iAs intake of the total population is much less than the PTWI of $15 \mu \mathrm{g} / \mathrm{kg}$ BW (WHO, 1988). However, the Joint FAO/WHO Expert Committee on Food Additives (JECFA) noted that PTWI is no longer appropriate to assess the risk of exposure to iAs (WHO/FAO, 2010). Meantime, PTWI, which is set on a logical and up-to-date basis, is also a useful approach for considering multiple exposure ways (Meharg and Raab, 2010). The present study shows that rice is the main contributor of iAs intake for the general population in China, which is in accordance with other studies elsewhere for populations reliant on rice as the staple food (Kile et al., 2007; Mondal and Polya, 2008; Zhu et al., 2008b). The mean iAs concentration in rice we derived from this study is $103 \mu \mathrm{g} / \mathrm{kg}$, which is very similar to the value used in a USA study (Zavala et al., 2008). In a global survey, Meharg et al. (2009) reported that median total As concentration in rice varied 7-fold, and iAs concentration was typically around or below $100 \mu \mathrm{g} / \mathrm{kg}$. However, much higher iAs has been reported in rice

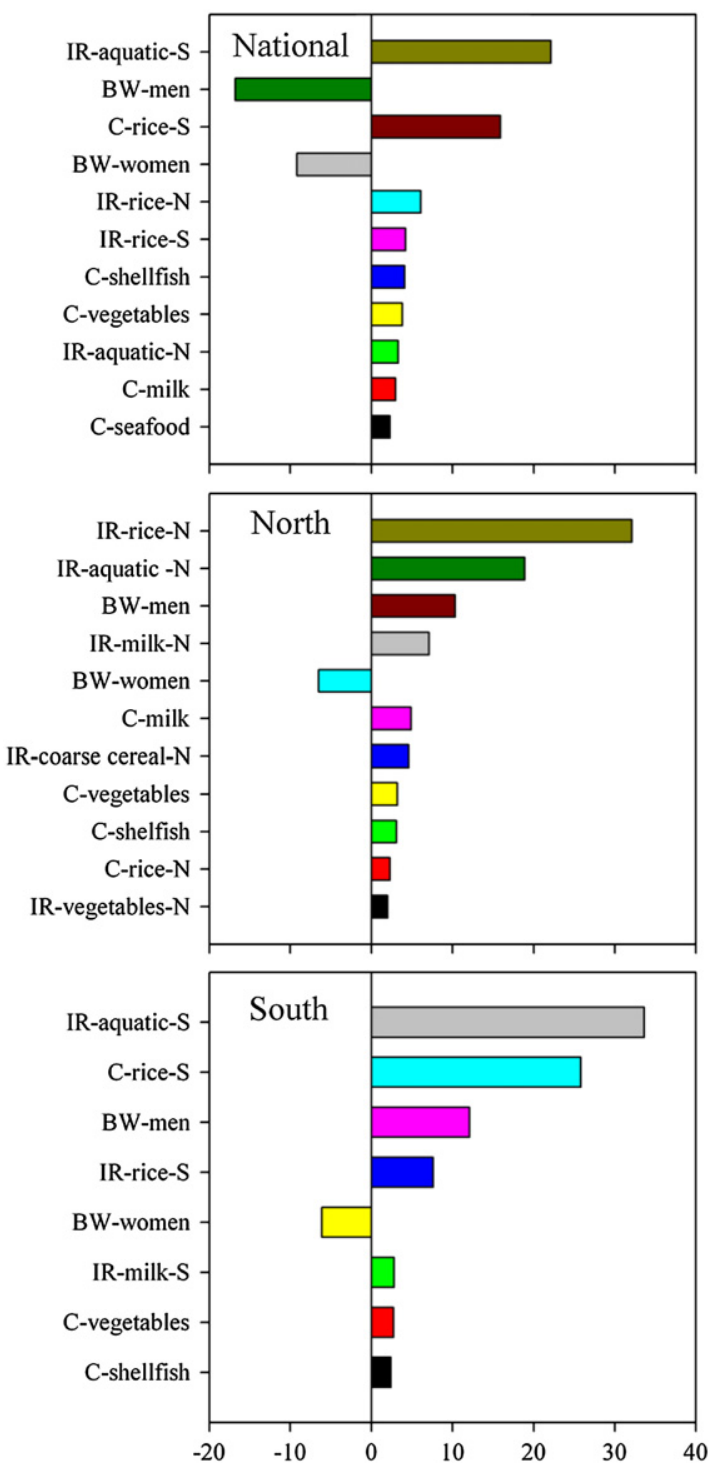

Fig. 3. Sensitivity analysis - contribution to variance (\%). C: inorganic arsenic concentration; IR: ingestion rate; N: northern region; S: Southern region.

samples from contaminated areas, such as mining-impacted soils in Hunan, China (Zhu et al., 2008a).

It is clear from the current study that iAs in rice is the main contributor to excess cancer risk to the general population in China through the food exposure pathway. Given that for most people in China, arsenic in water is not a major problem (Sun, 2004; Xia and Liu, 2004; Yu et al., 2007), controlling therefore, iAs in rice appears to be an urgent public health issue. Sensitivity analysis also indicated that the ingestion rates of aquatic products and rice and iAs concentration in rice in the South are the most relevant variables (Fig. 3). Future studies can take this information into consideration when collecting base data, as more effort of sampling should be concentrated on the most sensitive variables in order to better capture their variability. Since rice is the largest contributor of iAs intake, interventions limiting iAs in rice may be effective in reducing iAs intake from the Chinese population, and mitigating cancer risk. This conclusion is in agreement with the study conducted in a low arsenic groundwater region in Bangladesh (Mondal and Polya, 2008). Besides, controlling other factors like iAs concentrations in vegetable, shellfish and milk should also be paid attention to since the sensitivity analysis 
results indicated that they were also the key factors contributing to the cancer risk.

Although populations in urban and rural have very different dietary patterns, cancer risk from food iAs are comparable. This is due to the offsetting effect of rice and aquatic products, both having relatively high iAs concentrations but contrasting intake amounts of these two food types for the urban and rural settings. The difference in cancer risk between coastal and inland population may be mainly derived from the difference in aquatic products intake. The difference between the North and the South may be largely due to rice consumption, with the population in the North consuming much less rice. Animal-derived foodstuffs have minimal contribution to iAs intake for the Chinese population. Individual ILTR is always lower than the population estimate by about $40 \%$, which is low when compared to the relative interquartile range $\left(\left(p_{75}-p_{25}\right) / p_{50}\right)$ of the most relevant variables: $25.5 \%$ for body weight, $110 \%$ for ingestion of aquatic products, and $71 \%$ for concentration of iAs in rice in the Southern region. The individual estimate is within the interquartile range of the estimated population ILTR. Therefore, individual estimate is a good predictor of the population risk, but lacks the advantages of the probabilistic approach in regards to the identification of the most relevant variables, the richer statistical results and uncertainty analysis.

There are few papers concerning the impact on cancer risk caused by iAs through various food types, although many cancer risk calculations have taken a drinking water approach or just focused on individual food item like rice (see details in Supplementary data, Table S8). The estimated cancer risks in different countries and from various food pathways are quite variable. Mondal and Polya (2008) found that the median ILTR due to iAs intake of cooked rice was 76.2 per 100,000 and the median total risk from combined rice and water intake was 148 per 100,000 in West Bengal, India. The mean skin cancer risk was calculated to be only 24 per 100,000 for Japanese exposed to iAs through cooked hijiki consumption (Nakamura et al., 2008). Our estimated cancer risk for the total population from food is 177 per 100,000 (Table 4), which is similar to that of Bangladash from rice (221 per 10,000) (Meharg et al., 2009), but much higher than USA (10 per 100,000) (Tsuji et al., 2007). USEPA estimated skin cancer risk of 130 per 100,000 for American male exposed to $1 \mu \mathrm{g} / \mathrm{kg} \mathrm{BW} /$ day iAs from drinking water through a 76-year lifespan (Brown et al., 1989). Chen and Chen (1991) estimated a potency index for developing lung cancer from 460 per 100,000 to 2400 per 100,000 for an American male exposed to $1 \mu \mathrm{g} / \mathrm{kg}$ BW/day iAs, which is much higher than our estimation of 177 per 100,000 for the whole population exposed to $0.71 \mu \mathrm{g} / \mathrm{kg} \mathrm{BW} /$ day iAs. Compared to the cancer risks of the two studies mentioned above, our estimate is in the same order of magnitude and even much lower. Furthermore, our estimates in this study may even underestimate the effective risk because part of the dietary ingestion of arsenic has not been accounted for due to the lack of information on some other food types (e.g., oil, sugar, pastry, etc.), which may further add as much as $15 \%$ total food intake amount, and inevitably contribute to more iAs intake, though the available data is too scarce to allow the calculation of cancer risk.

Data from the International Agency for Research on Cancer (IARC) (http://globocan.iarc.fr/) that publishes estimates of cancer incidence based on country registries demonstrates that all cancers excluding non-melanoma skin cancer for the entire population indicates an incidence rate of 209.5 per 100,000 . Our estimated risk of 177 per 100,000 was much close to actual value. However, it should be kept in mind that many other agents like cadmium in food can also cause the cancers (Nawrot et al., 2006), and iAs is only one of them. Therefore, the cancer risk might be overestimated by our model.

\section{Conclusions}

There are very few epidemiological studies addressing the issue of iAs intake from food in China. Future studies to understand the link between food iAs intake and health outcomes, such as biomarkers and body burden (e.g. urine and hair As concentrations), are highly needed in China. Since China is such a vast country and has very diverse dietary patterns, any study attempting to understand this link should be conducted for specific regions, and perhaps for representative ethnic groups. Such zoom-in studies should then be integrated and be scaled up, so that a better picture of iAs exposure through food in China can be drawn. Although deterministic and probabilistic risk assessment models were both used to evaluate the cancer risk, the probabilistic model was better in identifying the most relevant factors of cancer risk and uncertainty analysis. Therefore, the model can provide a tool to consider the pros and cons of various schemes to mitigate iAs intake. Furthermore, these studies will equally be useful for the assessment of risks associated with other toxic chemicals or iAs through food in other countries.

$\begin{array}{ll}\text { Abbreviations } \\ \text { As } & \text { arsenic } \\ \text { LE } & \text { lifetime expectancy } \\ \text { BW } & \text { body weight } \\ \text { C } & \text { inorganic arsenic concentration } \\ \text { CNNHS } & \text { China National Nutrition and Health Survey } \\ \text { CSF } & \text { cancer slope factor } \\ \text { EDI } & \text { estimated daily intake } \\ \text { ED } & \text { exposure duration } \\ \text { EF } & \text { exposure frequency } \\ \text { EFSA } & \text { European Food and Safety Authority } \\ \text { FAO } & \text { Food and Agriculture Organization of the United Nations } \\ \text { FAOSTAT } & \text { FAO Statistical Database } \\ \text { iAs } & \text { inorganic arsenic } \\ \text { IARC } & \text { International Agency for Research on Cancer } \\ \text { IR } & \text { ingestion rate } \\ \text { IRIS } & \text { Integrated Risk Information System } \\ \text { JECFA } & \text { Joint FAO/WHO Expert Committee on Food Additives } \\ \text { ILTR } & \text { incremental lifetime cancer risk } \\ \text { NBS } & \text { National Bureau of Statistics } \\ \text { NRC } & \text { National Research Council } \\ \text { pdf } & \text { probability density function } \\ \text { EDI } & \text { estimated daily intake } \\ \text { PTWI } & \text { provisional tolerable weekly intake } \\ \text { RfD } & \text { reference dose } \\ \text { USEPA } & \text { United States Environmental Protection Agency } \\ \text { WHO } & \text { World Health Organization } \\ & \end{array}$

\section{Acknowledgments}

This work was financially supported by the Ministry of Science and Technology (2009DFB90120).

\section{Appendix A. Supplementary data}

Supplementary data to this article can be found online at doi:10.1016/j.envint.2011.05.007.

\section{References}

Abernathy CO, Liu YP, Longfellow D, Aposhian HV, Beck B, Fowler B, et al. Arsenic: health effects, mechanisms of actions, and research issues. Environ Health Perspect 1999;107(7):593-7.

Ahsan H, Chen Y, Parvez F, Zablotska L, Argos M, Hussain I, et al. Arsenic exposure from drinking water and risk of premalignant skin lesions in Bangladesh: baseline results from the health effects of arsenic longitudinal study. Am J Epidemol 2006;163(12): $1138-48$.

Argos M, Kalra T, Rathouz P, Chen Y, Pierce B, Parvez F, et al. Arsenic exposure from drinking water, and all-cause and chronic-disease mortalities in Bangladesh (HEALS): a prospective cohort study. Lancet 2010;376(9737):252-8. 
ATSDR (Agency for Toxic Substances and Disease Registry). Toxicological profile information sheet, visited; Agency for Toxic Substances and Disease Registry, Public Health Service, U.S. Department of Health and Human Services. Available: http:// www.atsdr.cdc.gov/toxpro2.html\#p 2010. [accessed 7 December, 2010].

Baeyens W, Gao Y, De Galan S, Bilau M, Van Larebeke N, Leermakers M. Dietary exposure to total and toxic arsenic in Belgium: importance of arsenic speciation in North Sea fish. Mol Nutr Food Res 2009;53(5):558-65.

Brown KG, Boyle KE, Chen CW, Gibb HJ. A dose-response analysis of skin cancer from inorganic arsenic in drinking water. Risk Anal 1989;9(4):519-28.

Carbonell-Barrachina AA, Signes-Pastor AJ, Vázquez-Araújo L, Burló F, Sengupta B. Presence of arsenic in agricultural products from arsenic-endemic areas and strategies to reduce arsenic intake in rural villages. Mol Nutr Food Res 2009;53(5): 531-41.

Chen CW, Chen CJ. Integrated quantitative cancer risk assessment of inorganic arsenic. In: Wen CP, editor. Proceedings of the Symposium on Health Risk Assessment on Environmental, Occupational and Lifestyle Hazards. Academia Sinica Taipei: Institute of Biomedical Sciences; 1991. p. 66.

Chen Y, Parvez F, Gamble M, Islam T, Ahmed A, Argos M, et al. Arsenic exposure at low-tomoderate levels and skin lesions, arsenic metabolism, neurological functions, and biomarkers for respiratory and cardiovascular diseases: review of recent findings from the health effects of arsenic longitudinal study (HEALS) in Bangladesh. Toxicol Appl Pharmacol 2009;239(2):184-92.

China Food Standard Agency. Maximum levels of contaminants in food. GB 2762; 2005

EFSA (European Food Safety Authority) Panel on Contaminants in the Food Chain (CONTAM). Scientific opinion on arsenic in food. EFSA J 2009;7(10):1351. [199pp].

FAOSTAT (Food and Agricuture Organization of the Unitied Nations statistical databases). FAO statistical databases. Available: http://faostat.fao.org/site/368/DesktopDefault. aspx? PageID=368\#ancor 2005. [accessed 7 December, 2010].

Georgopoulos PG, Wang SW, Yang YC, Xue J, Zartarian VG, Mccurdy T, et al. Biologically based modeling of multimedia, multipathway, multiroute population exposures to arsenic. J Expo Sci Environ Epidemiol 2007;18(5):462-76.

Han YF, Zhang JG, Zhang ZS. Regional geography of China. Guangdong: Guangdong Higher Education Press; 2009.

IARC (International Agency for Research on Cancer). Arsenic and inorganic arsenic compounds. IARC monographs on the evaluation of carcinogenic risk of chemicals to man. Some inorganic and organometallic compounds, 2. Lyon, IARC; 1973. p. $48-73$.

IRIS (Integrated Risk Information System). Arsenic, inorganic. (CASRN 7440-38-2) Available: http://www.epa.gov/ncea/iris/subst/0278.htm\#reforal 1988. [accessed 19 September, 2010].

Jin SG. Survey report on the nutrition and health of Chinese residents: dataset on the status of nutrition and health in 2002. Beijing: People's Hygeiene Press; 2008.

Kile M, Houseman E, Breton C, Smith T, Quamruzzaman Q, Rahman M, et al. Dietary arsenic exposure in Bangladesh. Environ Health Perspect 2007;115(6):889-93.

Kozul CD, Ely KH, Enelow RI, Hamilton JW. Low-dose arsenic compromises the immune response to influenza A infection in vivo. Environ Health Perspect 2009;117(9): 1441-7.

Li XW, Gao JQ, Wang YF, Chen JS. 2000 Chinese total dietary study - the dietary arsenic intakes. Wei Sheng Yan Jiu 2006a;35(1):63-6. [in Chinese].

Li Y, Wang YB, Gou X, Su YB, Wang G. Risk assessment of heavy metals in soils and vegetables around non-ferrous metals mining and smelting sites, Baiyin, China. J Environ Sci 2006b;18(6):1124-34.

Liu S, Li X, Zhang M. Scenario analysis on urbanization and rural-urban migration in China, Interim Report IR-03-036. (International Institute for Applied Systems Analysis, Vienna, Austria). Available: http://www.iiasa.ac.at/Admin/PUB/Documents/IR-03036.pdf 2003. [accessed 4 May, 2011]

Lubin JH, Beane Freeman LE, Cantor KP. Inorganic arsenic in drinking water: an evolving public health concern. J Natl Cancer Inst 2007;99(12):906-8.

Luo KL, Zhang XM, Chen CH, Lu YL. Estimate of arsenic emission amount from the coal power stations in China. Chin Sci Bull 2004;49(20):2183-9.

Meacher DM, Menzel DB, Dillencourt MD, Bic LF, Schoof RA, Yost LJ, et al. Estimation of multimedia inorganic arsenic intake in the US population. Hum Ecol Risk Assess 2002;8(7):1697-721.

Meharg AA, Raab A. Getting to the bottom of arsenic standards and guidelines. Environ Sci Technol 2010;44(12):4395-9.

Meharg AA, Deacon C, Campbell RCJ, Carey AM, Williams PN, Feldmann J, et al. Inorganic arsenic levels in rice milk exceed EU and US drinking water standards. J Environ Monit 2008;10(4):428-31.

Meharg AA, Williams PN, Adomako E, Lawgali YY, Deacon C, Villada A, et al. Geographical variation in total and inorganic arsenic content of polished (white) rice. Environ Sci Technol 2009;43(5):1612-7.
Mondal D, Polya DA. Rice is a major exposure route for arsenic in Chakdaha block, Nadia district, West Bengal, India: a probabilistic risk assessment. Appl Geochem 2008;23(11):2987-98.

Mondal D, Banerjee M, Kundu M, Banerjee N, Bhattacharya U, Giri AK, et al. Comparison of drinking water, raw rice and cooking of rice as arsenic exposure routes in three contrasting areas of West Bengal, India. Environ Geochem Health 2010;32(6): 463-77.

Nakamura Y, Narukawa T, Yoshinaga J. Cancer risk to Japanese population from the consumption of inorganic arsenic in cooked hijiki. J Agric Food Chem 2008;56(7): 2536-40.

Navas-Acien A, Silbergeld EK, Pastor-Barriuso R, Guallar E. Arsenic exposure and prevalence of type 2 diabetes in US adults. JAMA 2008;300(7):814-22.

Nawrot T, Plusquin M, Hogervorst J, Roels HA, Celis H, Thijs L, et al. Environmental exposure to cadmium and risk of cancer: a prospective population-based study. Lancet Oncol 2006;7(2):119-26.

NBS (National Bureau of Statistics). Results of the national 1\% population sample census in 2005. Beijing: China Statistics Press; 2007

NRC (National Research Council). Arsenic in drinking water: 2001 update. Washington, DC: National Academy Press; 2001.

Schoof R, Yost L, Eickhoff J, Crecelius E, Cragin D, Meacher D, et al. A market basket survey of inorganic arsenic in food. Food Chem Toxicol 1999;37(8):839-46.

Smith AH, Steinmaus CM. Health effects of arsenic and chromium in drinking water: recent human findings. Annu Rev Public Health 2009;30:107-22.

Sun G. Arsenic contamination and arsenicosis in China. Toxicol Appl Pharmacol 2004;198(3):268-71.

Sun GX, Williams PN, Zhu YG, Deacon C, Carey AM, Raab A, et al. Survey of arsenic and its speciation in rice products such as breakfast cereals, rice crackers and Japanese rice condiments. Environ Int 2009;35(3):473-5.

Tsuji JS, Yost LJ, Barraj LM, Scrafford CG, Mink PJ. Use of background inorganic arsenic exposures to provide perspective on risk assessment results. Regul Toxicol Pharmacol 2007;48(1):59-68.

USEPA (United States Environmental Protection Agency). Toxicological review of inorganic arsenic. Draft document. EPA/635/R-10/001. Washington, DC, USA: USEPA; 2010. p. 575.

Wade TJ, Xia Y, Wu K, Li Y, Ning Z, Le XC, et al. Increased mortality associated with wellwater arsenic exposure in Inner Mongolia, China. Int J Environ Res Public Health 2009;6(3):1107-23.

WHO (World Health Organization). Summary of evaluations performed by the Joint FAO/WHO Expert Committee on Food Additives: Arsenic. Geneva: WHO; 1988

WHO/FAO (Food and Agriculture Organization of the United Nations). Summary and conclusions of the seventy-second meeting. Food contaminants. Rome, 16-25 February 2010. Available: http://www.fao.org/ag/agn/agns/jecfa_output_en.asp 2010. [accessed 8 December, 2010].

Williams PN, Price AH, Raab A, Hossain SA, Feldmann J, Meharg AA. Variation in arsenic speciation and concentration in paddy rice related to dietary exposure. Environ Sci Technol 2005;39:5531-40.

Williams PN, Villada A, Deacon C, Raab A, Figuerola J, Green AJ, et al. Greatly enhanced arsenic shoot assimilation in rice leads to elevated grain levels compared to wheat and barley. Environ Sci Technol 2007;41(19):6854-9.

Williams PN, Lei M, Sun GX, Huang Q, Lu Y, Deacon C, et al. Occurrence and partitioning of cadmium, arsenic and lead in mine impacted paddy rice: Hunan, China. Environ Sci Technol 2009;43(3):637-42.

Xia Y, Liu J. An overview on chronic arsenism via drinking water in PR China. Toxicology 2004;198(1-3):25-9.

Xue J, Zartarian V, Wang SW, Liu SV, Georgopoulos P. Probabilistic modeling of dietary arsenic exposure and dose and evaluation with 2003-2004 NHANES data. Environ Health Perspect 2010;118(3):345-50.

Yang XG, Li YP, Ma GS, Hu XQ, Wang JZ, Cui ZH, et al. Study on weight and height of the Chinese people and the differences between 1992 and 2002. Zhong Hua Liu Xing Bing Xue Za Zhi 2005;26(7):489-93. [in Chinese].

Yu G, Sun D, Zheng Y. Health effects of exposure to natural arsenic in groundwater and coal in China: an overview of occurrence. Environ Health Perspect 2007;115(4): 636-42.

Zavala YJ, Gerads R, Gorleyok H, Duxbury JM. Arsenic in rice: II. Arsenic speciation in USA grain and implications for human health. Environ Sci Technol 2008;42(10): 3861-6.

Zhu YG, Sun GX, Lei M, Teng M, Liu YX, Chen NC, et al. High percentage inorganic arsenic content of mining impacted and nonimpacted Chinese rice. Environ Sci Technol 2008a;42(13):5008-13.

Zhu YG, Williams PN, Meharg AA. Exposure to inorganic arsenic from rice: a global health issue? Environ Pollut 2008b;154(2):169-71. 